\title{
Lumbar muscle size and locations from CT scans of 96 women of age 40 to 63 years
}

\author{
D B Chaffin PhD \\ M S Redfern PhD \\ M Erig MS \\ S A Goldstein PhD'
}

Center for Ergonomics and

'Biomechanics, Trauma and Sports Medicine Laboratory, Orthopaedic Surgery, The University of Michigan, USA

\begin{abstract}
Summary
Computed tomography scans of 96 women aged between 40 and 63 years were systematically measured to determine torso muscle moment arms and cross-sectional areas at $L_{2} / L_{3}, L_{3} / L_{4}$ and $L_{d} L_{5}$ disc levels. The major findings were as follows: (1) the mean muscle moment arm and area data were not different bilaterally; (2) psoas, quadratus lumborum, and latissimus dorsi muscle moment arms consistently changed at the three disc levels, while erector spinae, rectus abdominis, transverse abdominis and the oblique muscles remained about the same distance from the three disc centroids; (3) psoas and quadratus lumborum muscles increased in mean size at the lower levels and (4) gross torso anthropometry and body weight had a significant $(P<0.01)$ but varied correlation ( $r$ from 0.12 to 0.65 ) with the size of the erector spinae and psoas muscles, and with the moment arms of the rectus abdominis, transverse abdominis, latissimus dorsi, and oblique muscles.
\end{abstract}

\section{Relevance}

As biomechanical models become more refined in their ability to predict stresses operating on the spinal column during specific manual exertions, accurate muscle moment arm and muscle area data are needed. This study presents data on a group of people (women of ages between 40 and 63 ) who are thought to be at increased risk of developing low-back pain, particularly if involved in heavy manual labour. It is believed that the data are important in refining present and future low-back biomechanical models for this strata of the population. The finding of left-right symmetry in this large sample also supports the use of bilateral clinical comparisons of muscle size and location.

Key words: Low-back biomechanical models, torso anthropometry, torso musculature

\section{Introduction}

Biomechanical models of the lumbar spine have shown that its movement and stability in the physiological range are almost completely dependent upon torso muscle actions. As these biomechanical models have become more refined, their ability to accurately depict the forces and moments acting on the spinal motion

Received: 12 December 1988

Accepted: 29 August 1989

Correspondence and reprint requests to: Dr D B Chaffin, Centre for Ergonomics, 1205 Beal-IOE Building. Ann Arbor, Michigan 48109. 2117, USA

(C) 1990 Butterworth \& Co (Publishers) Ltd 0268-0033/90/01009-08 segments has been shown to be greatly dependent upon the relative size and locations of the torso muscles. Studies by Chaffin et al. ${ }^{1}$ and McGill and Norman ${ }^{2}$ have shown that simplifying assumptions about the moment arm distances of the muscles relative to the spinal motion segments could cause errors as great as $40 \%$ in predictions of the spinal forces.

It is also clear from a limited number of cadaver dissections performed by Bogduk ${ }^{3}$ and Macintosh and Bogduk $^{4}$ that longitudinal torso muscles (e.g. erector spinae, quadratus lumborum, rectus abdominis, psoas and latissimus dorsi, which are all included in this study) are not parallel to the lumbar spinal column. If confirmed in larger population studies, then biomechanical 
models, of spinal forces at various segmental levels will need to recognize more fully the complexity related to the non-parallel forces of these muscles, as shown by McGill and Norman ${ }^{5}$.

Recently, improved tissue-imaging methods have provided the means to better determine the size and location of muscles of the torso. Using computed tomography (CT) scanning methods, several investigators have reported statistical results obtained from small groups of volunteers $(n=4$ to $n=56)$ (Reid ${ }^{6}$. Németh and Ohlsén ${ }^{7}$, Reid et al. ${ }^{8}$, McGill et al. ${ }^{9}$ and Kumar ${ }^{1(\prime)}$ ). Both men and women of varying ages were included in these studies and differences between men and women were found throughout. The results varied widely between studies, possibly due to smaller sample sizes.

The objectives of the present study were defined to address some of the issues raised by the previously cited work. These were as follows:

(1) to report the results of a larger sample $(n=96)$ of a specific population (older females) and to compare the results with those obtained by others who used different population strata,

(2) to evaluate the cross-sectional areas and locations of selected torso muscles from scans at three different lumbar levels,

(3) to evaluate the left-right symmetry of the torso muscles in this group,

(4) to determine whether gross anthropometric data on the subjects correlate with torso muscle size and location.

The choice of older females was motivated by the observation that an increasing number of this population group are becoming involved in heavy manual lifting jobs in industry. Unfortunately, they may be at increased risk of low-back pain as indicated by a recent epidemiological study in Sweden (Svensson et al. ${ }^{11}$ ). A question regarding their risk level also has been raised by biomechanical studies, which disclose that (1) lumbar disc compression-failure forces in females are approximately $25 \%$ lower than that of males, (2) that the bone mineral content of vertebrae is significantly lower in older female spines than in the male spines and (3) that compression-failure forces are highly correlated with disc area and bone mineral content (Yoganandan et al. ${ }^{12}$ and Brinckmann et al. ${ }^{13}$ ). For these reasons, it was believed that good statistical data were needed on the torso muscles of older females to assure that future biomechanical studies would consider any variations from the more often reported male data.

\section{Methods}

\section{Data collection}

Transverse scans of the lumbar region were obtained on a Technicare 1440 HPS computed tomography system. The three transverse levels were identified using a scout view (digital lateral radiograph). Scans were made perpendicular to the table with the subject's knees and hips flexed in order to minimize the lordotic curve. A full description of this technique was presented in Cody et al. ${ }^{14}$. All scans were made using a bone protocol (130 $\mathrm{kV}, 100 \mathrm{~mA}, 4$ seconds) with a full field of $40 \mathrm{~cm}$ and a convolution filter with no edge enhancement or smoothing. For each patient, $1 \mathrm{~mm}$ thick scanned segments were obtained spanning at least two disc levels from $L_{2}$ through to $\mathrm{L}_{5}$. All subjects were placed supine on the gantry with a calibration phantom positioned beneath their torso

After scanning, the reconstructed images $(512 \times 512$ pixels) were stored on magnetic tape and transferred to an Apollo DN3000 computer for analysis. Prior to evaluation of each scan, each image was scaled utilizing a projected reference grid superimposed by the CT scanner onto the scan image. Rotation of the $x, y$ axes to represent the sagittal and coronal planes of the subjects was accomplished by defining a coordinate axis referenced to a line defined by a point in the centroid of the disc and one central to the posterior process. This line defined the $y$ (sagittal plane) axis of the individual from which all other $x, y$ coordinates would be represented. The centroid of the disc was defined as the 0,0 value for the $x, y$ coordinate system. The perimeters of each muscle of interest, the torso and the disc were traced with a graphics mouse control. Muscle-group areas were defined by constructing sequential trapezoidal sectors completely filling the anatomical region of interest. Figure 1 depicts this procedure for the erector spinae muscle. By superposition of the areas of each trapezoid, the total cross-sectional area was estimated. The centroids of the muscles and discs were calculated by determining the centroid $x, y$ coordinates of each trapezoidal area. Area-weighted mean $x, y$ coordinates were then computed for each muscle and disc.

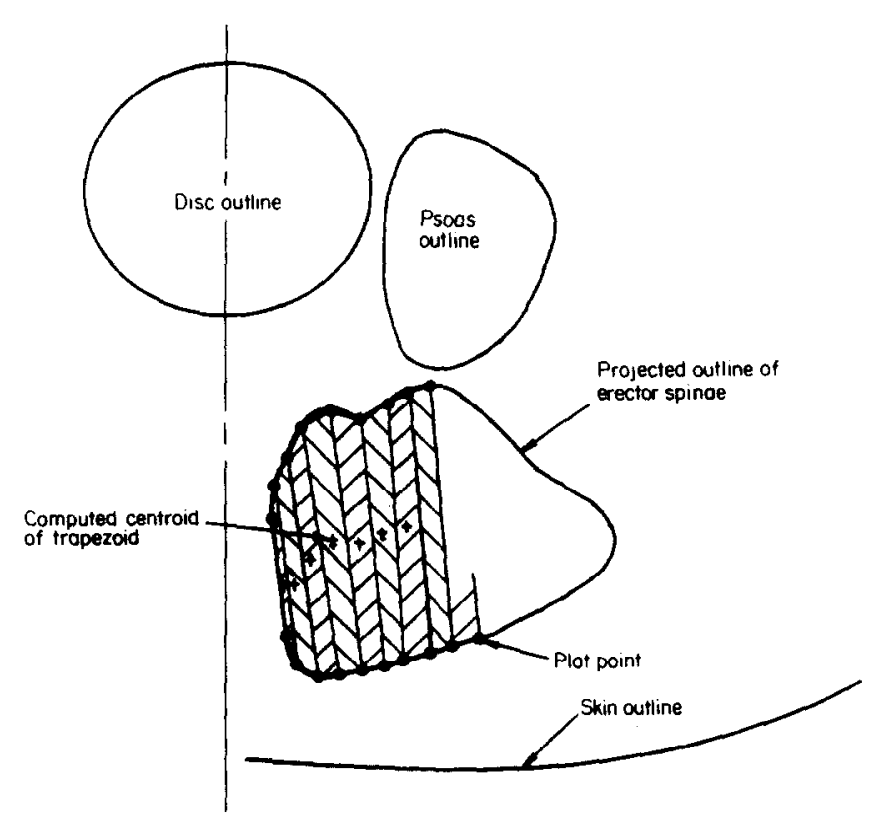

Figure 1. Illustration of sequential trapezoid fitting method used to estimate area and centroid locations of muscles. 


\section{Data analysis}

Eight muscles were measured and analysed from the CT data. These were the erector spinae, rectus abdominis, internal oblique, external oblique, latissimus dorsi, psoas, quadratus lumborum and the transverse abdominis. Measurements were made of the distance of each muscle's centroid from the disc centroids (or origin) in the $x$ direction and $y$ direction, and each muscle's cross-sectional area. These variables were obtained at each lumbar level $\left(\mathrm{L}_{2} / \mathrm{L}_{3}, \mathrm{~L}_{3} / \mathrm{L}_{4}\right.$ and $\left.\mathrm{L}_{4} / \mathrm{L}_{5}\right)$ on both the right and left sides. Therefore, 16 muscles were analysed at two or three spinal levels for each subject.

Mean and standard deviations were computed for each variable, and also for each variable with the data stratified by lumbar disc level $\left(\mathrm{L}_{2} / \mathrm{L}_{3}, \mathrm{~L}_{3} / \mathrm{L}_{4}\right.$ and $\left.\mathrm{L}_{4} / \mathrm{L}_{5}\right)$ and by the left and right sides of the body. ANOVA and $t$-tests of mean differences were used to determine if the mean values differed at the various disc levels and on the left or right side. Finally, the data were regressed on the anthropometric variables of gross body weight $(\mathrm{kg})$, stature $(\mathrm{cm})$, trunk area $\left(\mathrm{cm}^{2}\right)$, trunk diameter $(x$ direction in the coronal plane, $\mathrm{cm}$ ) and trunk diameter ( $y$ direction in the sagittal plane, $\mathrm{cm}$ ).

\section{Subject population}

The population of 96 women was obtained from a study being conducted at the Henry Ford Hospital, Detroit, Michigan. These subjects were volunteers in a crosssectional study of spinal osteoporosis as detected by quantitative computed tomography scanning. This group of subjects represented the normal control population of healthy, active individuals at the time of the study, and were anthropometrically similar to individuals of the same general age, as shown in Table 1.

The means and standard deviations for the muscle moment arm $x$ and $y$ centroid locations (relative to the centroid of the discs) are presented in Table 2. Threeway ANOVA with $\alpha<0.001$ error discloses that the mean values for many of the muscles varied between the three segmental levels, as shown by asterisks in Table 2 . What was perhaps most unexpected was that neither the mean $\boldsymbol{x}$ or $\boldsymbol{y}$ distances could be shown to vary significantly in the erector spinae and rectus abdominis muscles at the three different levels. A plot of the $x$ and $y$ mean values is given in Figure 2. Inspection of this plot indicates consistent trends in the muscle moment arm lengths with segmental levels.

The means and standard deviations of the muscle cross-sectional areas are presented in Table 3 . No significant differences were found in the erector spinae, rectus abdominis, external oblique and latissimus dorsi muscles. The psoas and quadratus lumborum showed the greatest consistent changes, both becoming larger at lower levels. A plot of the mean values for the crosssections. is given in Figure 3.

As to the question of left-right symmetry, the mean values obtained from the left and right side were evaluated using a Student $t$-test with an error of $\alpha<$ $0 \cdot 01$. No significant difference could be found. This result had the practical effect of assuring that the data were internally consistent, since a measurement or coding error would probably affect a data value on one side but not the other.

The question of whether the gross anthropometry of an individual correlates with torso muscle moment arms and/or cross-sectional area was also evaluated. Body weight, stature and trunk area were used as independent variables in regressions of the muscle cross-sectional areas. All combinations of these variables including second order models with interactions were used (Table 4). Minimal correlations were found with muscle areas. Only the cross-sectional areas of the erector spinae and psoas correlated, with $r^{2}$ values as great as $0 \cdot 12$ to $0 \cdot 26$, and with error terms between 14 and $24 \%$. While these are low correlations, it is interesting to note that increased body weight appears to correlate with increased size of the erector spinae, as does height and trunk area. The psoas effect is not as clear, with weight and height having counteracting effects, and trunk area having a positive correlation with larger muscle area.

The $x$ and $y$ moment arm values were regressed on body weight, height, trunk breadth, trunk depth, and trunk area. By inspection of the Pearson Correlation Matrix, the variables that best explained the variance in $x$ and $y$ moment arms were chosen. Resulting regression models, together with indicators of how well they fit the data, are displayed in Tables 5 and 6 . The rectus abdominis was the only muscle which varied consistently in both the $y$ and $x$ directions with the independent variables. Body weight and abdominal depth were the most consistent indicators of increased moment arm distances for this muscle. Both of the oblique muscles,

Table 1. Population statistics

\begin{tabular}{|c|c|c|c|c|}
\hline \multirow[b]{2}{*}{ Variable } & \multicolumn{2}{|c|}{ This study } & \multicolumn{2}{|c|}{ US survey strata } \\
\hline & Mean & $S D$ & Mean & $S D$ \\
\hline 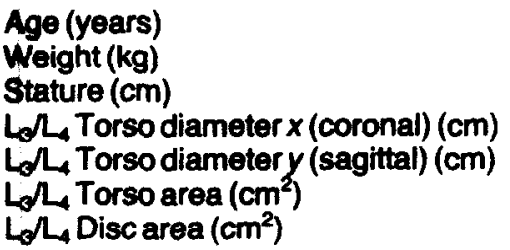 & $\begin{array}{c}49 \cdot 6 \\
67 \cdot 6 \\
163 \cdot 1 \\
21 \cdot 7 \\
13 \cdot 6 \\
509 \\
15 \cdot 2\end{array}$ & $\begin{array}{r}5 \cdot 9 \\
13 \cdot 1 \\
5 \cdot 8 \\
2 \cdot 9 \\
2 \cdot 6 \\
168 \\
2 \cdot 3\end{array}$ & $\begin{array}{r}68.2 \\
161.5 \\
- \\
- \\
-\end{array}$ & $\begin{array}{r}14 \cdot 6 \\
5 \cdot 8 \\
- \\
- \\
-\end{array}$ \\
\hline
\end{tabular}

"US population data are for women age 45-54 years 
Table 2. Absolute mean and standard deviations of the muscle moment arms $(\mathrm{cm}) x$ and $y$ components with segmental levels

\begin{tabular}{|c|c|c|c|c|c|c|c|c|c|c|c|}
\hline & Muscle & Side & $\begin{array}{c}\text { (Sampl } \\
\text { Mean }\end{array}$ & $\begin{array}{c}-3 \\
\text { SD } 31)\end{array}$ & $\begin{array}{c}\text { Segme } \\
\text { (Samp) } \\
\text { Mean }\end{array}$ & $\begin{array}{l}\text { allevel } \\
-4 \\
\text { size 96) } \\
S D\end{array}$ & $\begin{array}{c}\text { L } \\
\text { (Sampl } \\
\text { Moan }\end{array}$ & $\begin{array}{l}-5 \\
\text { size 66) } \\
\text { SD }\end{array}$ & $\begin{array}{l}\text { Segme } \\
\text { gra } \\
\text { aver } \\
\text { Mean }\end{array}$ & $\begin{array}{l}\text { ental } \\
\text { ind } \\
\text { age } \\
S D\end{array}$ & $\begin{array}{c}\text { Significance of } \\
\text { Difference }\end{array}$ \\
\hline & Erector spinae & $\begin{array}{l}\text { left } \\
\text { riaht }\end{array}$ & $\begin{array}{l}3.3 \\
3.4\end{array}$ & $\begin{array}{l}0.4 \\
0.4\end{array}$ & $\begin{array}{l}3.4 \\
3.4\end{array}$ & $\begin{array}{l}0.4 \\
0.4\end{array}$ & $\begin{array}{l}3.5 \\
35\end{array}$ & 0.4 & $\begin{array}{l}3.4 \\
3.5\end{array}$ & 0.4 & \\
\hline & Rectus abdominis & left & $4 \cdot 2$ & 1.0 & $4 \cdot 3$ & $1 \cdot 2$ & $4 \cdot 1$ & 1.1 & $4 \cdot 2$ & $1 \cdot 1$ & \\
\hline & & right & 4.4 & 1.2 & $4 \cdot 3$ & 1.1 & 4.2 & $1 \cdot 1$ & 4.3 & $1 \cdot 1$ & \\
\hline$x$ & Internal oblique & left & $10 \cdot 9$ & 1.5 & $11 \cdot 4$ & 1.6 & 11.4 & $2 \cdot 0$ & $11 \cdot 3$ & 1.7 & * \\
\hline & & right & $10 \cdot 9$ & 1.5 & $11 \cdot 3$ & 1.6 & 11.5 & $2 \cdot 0$ & $11 \cdot 1$ & 1.5 & * \\
\hline Coronal & External oblique & left & $11 \cdot 7$ & 1.4 & $12 \cdot 2$ & 1.6 & $12 \cdot 3$ & $2 \cdot 0$ & $12 \cdot 1$ & 1.7 & \\
\hline & & right & $11 \cdot 7$ & 1.5 & $12 \cdot 0$ & 1.6 & $12 \cdot 1$ & 1.4 & $12 \cdot 0$ & 1.7 & \\
\hline plane & Latissimus dorsi & left & 9.9 & $1 \cdot 2$ & $10 \cdot 7$ & $1 \cdot 4$ & $11 \cdot 8$ & 1.5 & $10 \cdot 7$ & 1.5 & * \\
\hline & & right & $10 \cdot 0$ & $1 \cdot 1$ & $10 \cdot 6$ & 1.6 & 11.9 & $1 \cdot 1$ & $10 \cdot 7$ & 1.5 & * \\
\hline & Psoas & left & $3 \cdot 2$ & 0.4 & 3.8 & 0.4 & $4 \cdot 3$ & 0.4 & 3.9 & 0.5 & * \\
\hline & & right & $3 \cdot 3$ & 0.4 & 3.7 & 0.4 & $4 \cdot 4$ & 0.4 & 3.9 & 0.5 & * \\
\hline & Quadratus lumborum & left & 5.5 & 0.7 & $6 \cdot 5$ & 0.7 & $7 \cdot 5$ & 1.0 & $6 \cdot 6$ & $1 \cdot 0$ & * \\
\hline & & right & 5.6 & 0.8 & 6.5 & 0.7 & 7.4 & 0.8 & $6 \cdot 6$ & $1 \cdot 0$ & * \\
\hline & Transverse abdominis & left & $10 \cdot 3$ & 1.5 & 11.0 & $1 \cdot 7$ & $11 \cdot 0$ & 1.9 & 10.9 & 1.7 & \\
\hline & & right & 10.4 & 1.5 & $10 \cdot 8$ & 1.6 & $11 \cdot 0$ & 1.4 & $10 \cdot 8$ & 1.5 & \\
\hline & Erector spinae & left & 5.4 & 0.4 & $5 \cdot 3$ & 0.2 & $5 \cdot 4$ & 0.4 & 5.4 & 0.4 & \\
\hline & & right & $5 \cdot 4$ & 0.4 & $5 \cdot 2$ & 0.4 & $5 \cdot 2$ & 0.3 & $5 \cdot 3$ & 0.4 & \\
\hline & Rectus abdominis & left & $7 \cdot 2$ & $1 \cdot 6$ & $7 \cdot 2$ & 1.9 & $7 \cdot 0$ & $2 \cdot 0$ & $7 \cdot 1$ & 1.8 & \\
\hline & & right & $7 \cdot 0$ & 1.5 & $7 \cdot 0$ & 1.9 & $6 \cdot 9$ & $2 \cdot 0$ & $6 \cdot 9$ & 1.8 & \\
\hline$y$ & Internal oblique & left & $2 \cdot 5$ & 1.6 & $2 \cdot 0$ & 1.0 & $2 \cdot 8$ & $1 \cdot 3$ & $2 \cdot 4$ & 1.3 & * \\
\hline & & right & 2.4 & 1.4 & $2 \cdot 1$ & $1 \cdot 1$ & 3.0 & $1 \cdot 5$ & 2.4 & 1.3 & * \\
\hline Sagittal & External oblique & left & $2 \cdot 0$ & $1 \cdot 1$ & $2 \cdot 0$ & $1 \cdot 1$ & 3.0 & $1 \cdot 2$ & $2 \cdot 2$ & $1 \cdot 2$ & * \\
\hline & & right & $2 \cdot 2$ & $1 \cdot 3$ & $2 \cdot 3$ & $1 \cdot 2$ & $3 \cdot 0$ & $1 \cdot 3$ & $2 \cdot 5$ & 1.4 & \\
\hline plane & Lattissimus dorsi & left & 3.4 & $1 \cdot 1$ & $3 \cdot 0$ & $1 \cdot 0$ & 1.4 & $1 \cdot 3$ & $2 \cdot 8$ & $1 \cdot 3$ & * \\
\hline & & right & 3.6 & 0.9 & $3 \cdot 0$ & $1 \cdot 0$ & $1 \cdot 7$ & $1 \cdot 1$ & $2 \cdot 9$ & $1 \cdot 2$ & * \\
\hline & Psoas & left & 1.1 & 0.4 & 0.8 & 0.5 & 0.2 & 0.4 & 0.6 & 0.6 & * \\
\hline & & right & $1 \cdot 1$ & 0.3 & 0.8 & 0.4 & 0.2 & 0.5 & 0.6 & 0.6 & * \\
\hline & Quadratus lumborum & left & 3.5 & 0.5 & $3 \cdot 3$ & 0.6 & $2 \cdot 8$ & 0.6 & 3.2 & 0.7 & * \\
\hline & & right & $3 \cdot 6$ & 0.4 & $3 \cdot 2$ & 0.7 & $2 \cdot 8$ & 0.7 & 3.1 & 0.7 & * \\
\hline & Transverse abdominis & left & $2 \cdot 6$ & 1.7 & 1.8 & $1 \cdot 1$ & $2 \cdot 5$ & 1.1 & $2 \cdot 2$ & $1 \cdot 3$ & * \\
\hline & & right & 1.9 & 1.7 & 1.4 & $1 \cdot 1$ & $2 \cdot 4$ & 1.2 & 1.9 & $1 \cdot 3$ & * \\
\hline
\end{tabular}

\section{${ }^{*} P<0.001$}
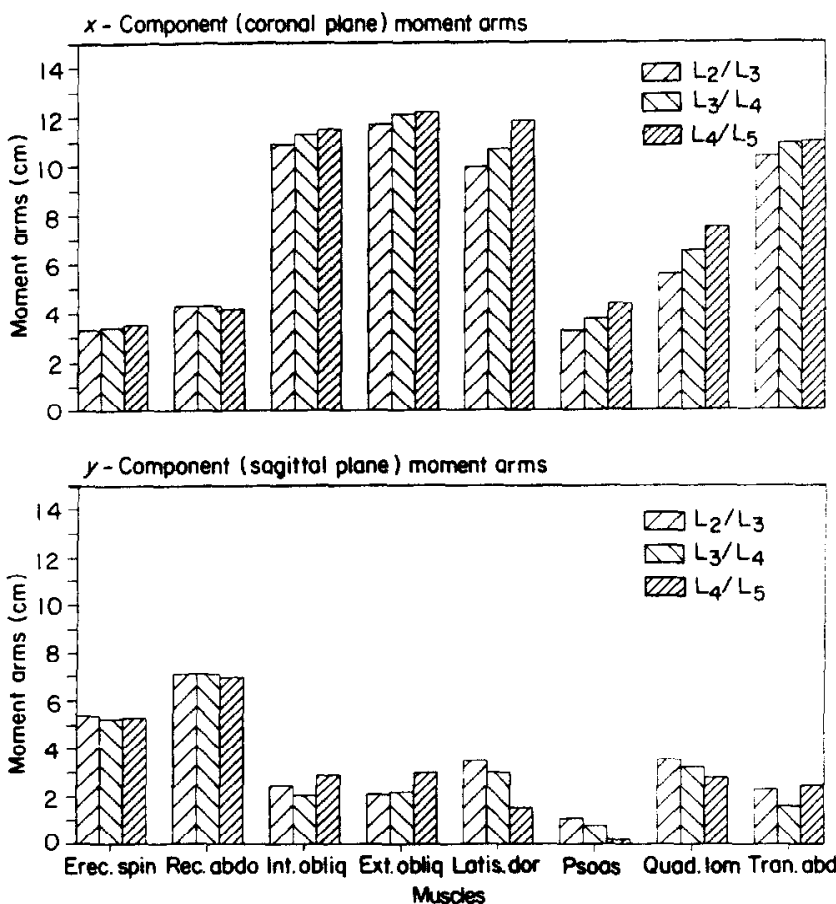

Figure 2. Absolute mean $x$ and $y$ moment arm values stratified by segmental levels. latissimus dorsi, and transverse abdominal muscles increased their moment arm $x$ distances (in the coronal plane) with body weight and trunk depth and breadth diameters. The erector spinae moment arms were not found to correlate with any of the independent variables.

\section{Discussion and conclusions}

The study represents an attempt at using CT data to develop a statistical database on muscle size and location representative of a designated strata of the population (i.e. older females). The 96 subjects were found to be reasonably representative of the US female population adjusted for age, based on their statures and body weights.

Since the scans were available at three spinal disc levels $\left(\mathrm{L}_{2} / \mathrm{L}_{3}, \mathrm{~L}_{3} / \mathrm{L}_{4}\right.$ and $\left.\mathrm{L}_{4} / \mathrm{L}_{5}\right)$, it was possible to statistically compare muscle sizes and locations at each level. This statistical evaluation disclosed that some significant differences in muscle size and moment arm distances existed in this population, depending on the spinal level being considered. A computer projection of the mean data for each spinal level is presented in Figure 4 along 
Table 3. Measured muscle areas $\left(\mathrm{cm}^{2}\right)$, torso area $\left(\mathrm{cm}^{2}\right)$ and disearea $\left(\mathrm{cm}^{2}\right)$ stratified by segmental levels

\begin{tabular}{|c|c|c|c|c|c|c|c|c|c|c|}
\hline \multirow[b]{2}{*}{ Muscle } & \multirow[b]{2}{*}{ Side } & \multicolumn{2}{|c|}{$\begin{array}{c}\mathrm{L}_{2} / \mathrm{L}_{3} \\
\text { (Sample size 31) }\end{array}$} & \multicolumn{2}{|c|}{$\begin{array}{c}\text { Segmental level } \\
L_{3} / L_{4} \\
\text { (Sample size 96) }\end{array}$} & \multicolumn{2}{|c|}{$\begin{array}{c}L_{4} / L_{5} \\
\text { (Sample size 66) }\end{array}$} & \multicolumn{2}{|c|}{$\begin{array}{l}\text { Segmental } \\
\text { grand } \\
\text { average }\end{array}$} & \multirow{2}{*}{$\begin{array}{c}\text { Significance of } \\
\text { Difference }\end{array}$} \\
\hline & & Mean & $S D$ & Mean & & Mean & $S D$ & Mean & $S D$ & \\
\hline Erector spinae & $\begin{array}{l}\text { left } \\
\text { right }\end{array}$ & $\begin{array}{l}17.9 \\
18.2\end{array}$ & $\begin{array}{l}3.1 \\
2.7\end{array}$ & $\begin{array}{l}18.5 \\
18.5\end{array}$ & $\begin{array}{l}3.0 \\
3.0\end{array}$ & $\begin{array}{l}17 \cdot 3 \\
17 \cdot 4\end{array}$ & $\begin{array}{l}3.0 \\
3.0\end{array}$ & $\begin{array}{l}18.0 \\
18.1\end{array}$ & $\begin{array}{l}3 \cdot 1 \\
3 \cdot 0\end{array}$ & \\
\hline Rectus abdominis & left & 3.4 & $1 \cdot 2$ & $3 \cdot 7$ & $1 \cdot 2$ & $4 \cdot 1$ & $1 \cdot 2$ & $3 \cdot 8$ & $1 \cdot 2$ & \\
\hline \multirow{2}{*}{ Internal oblique } & right & $3 \cdot 3$ & 1.6 & 3.7 & 1.1 & 4.0 & 1.0 & 3.8 & 1.2 & \\
\hline & $\begin{array}{l}\text { left } \\
\text { right }\end{array}$ & $\begin{array}{l}4.3 \\
4.0\end{array}$ & $\begin{array}{l}1.5 \\
1.4\end{array}$ & $\begin{array}{l}5.8 \\
5.3\end{array}$ & $\begin{array}{l}1.5 \\
1.3\end{array}$ & $\begin{array}{l}5 \cdot 2 \\
5 \cdot 3\end{array}$ & $\begin{array}{l}1.5 \\
1.8\end{array}$ & $\begin{array}{l}5 \cdot 3 \\
5 \cdot 1\end{array}$ & $\begin{array}{l}1.6 \\
1.6\end{array}$ & * \\
\hline \multirow[t]{2}{*}{ External oblique } & left & 5.5 & 1.6 & 6.0 & 1.4 & 6.0 & 1.6 & $5 \cdot 9$ & 1.5 & \\
\hline & right & 3.7 & $1 \cdot 2$ & $4 \cdot 4$ & 1.4 & $4 \cdot 6$ & $1 \cdot 4$ & $4 \cdot 3$ & 1.4 & \\
\hline \multirow[t]{2}{*}{ Lattissimus dorsi } & left & 1.4 & 0.6 & $1 \cdot 3$ & 0.5 & 1.5 & 0.6 & $1 \cdot 3$ & 0.5 & \\
\hline & right & 1.2 & 0.4 & 1.3 & 0.4 & $1 \cdot 3$ & 0.5 & 1.3 & 0.4 & \\
\hline \multirow[t]{2}{*}{ Psoas } & left & $5 \cdot 9$ & $1 \cdot 7$ & $8 \cdot 3$ & $1 \cdot 9$ & $9 \cdot 8$ & $2 \cdot 2$ & $8 \cdot 4$ & $2 \cdot 4$ & * \\
\hline & right & 5.8 & 1.5 & $8 \cdot 3$ & 1.9 & 9.8 & $2 \cdot 0$ & 8.4 & $2 \cdot 3$ & * \\
\hline \multirow[t]{2}{*}{ Quadratus lumborum } & left & $3 \cdot 3$ & 1.6 & 4.5 & 1.4 & 4.5 & $1 \cdot 3$ & $4 \cdot 3$ & 1.4 & * \\
\hline & right & 3.0 & 0.7 & $4 \cdot 1$ & $1 \cdot 2$ & $4 \cdot 6$ & 1.0 & $4 \cdot 1$ & 1.2 & $\star$ \\
\hline \multirow[t]{2}{*}{ Transverse abdominis } & left & $2 \cdot 6$ & 0.7 & $2 \cdot 6$ & 0.8 & $1 \cdot 9$ & 0.8 & $2 \cdot 4$ & 0.9 & * \\
\hline & right & $3 \cdot 4$ & 1.5 & $3 \cdot 6$ & $1 \cdot 9$ & $2 \cdot 6$ & 0.9 & $3 \cdot 2$ & $1 \cdot 2$ & * \\
\hline $\begin{array}{l}\text { Disc area }\left(\mathrm{cm}^{2}\right) \\
\text { Torso area }\left(\mathrm{cm}^{2}\right)\end{array}$ & & $\begin{array}{l}14 \cdot 2 \\
443\end{array}$ & 122 & $\begin{array}{l}15 \cdot 2 \\
509\end{array}$ & $168^{2 \cdot 3}$ & $\begin{array}{l}15 \cdot 3 \\
576\end{array}$ & $\begin{array}{c}2 \cdot 2 \\
159\end{array}$ & $\begin{array}{l}15 \cdot 1 \\
521\end{array}$ & 164 & * \\
\hline
\end{tabular}

$\cdot P<0.001$

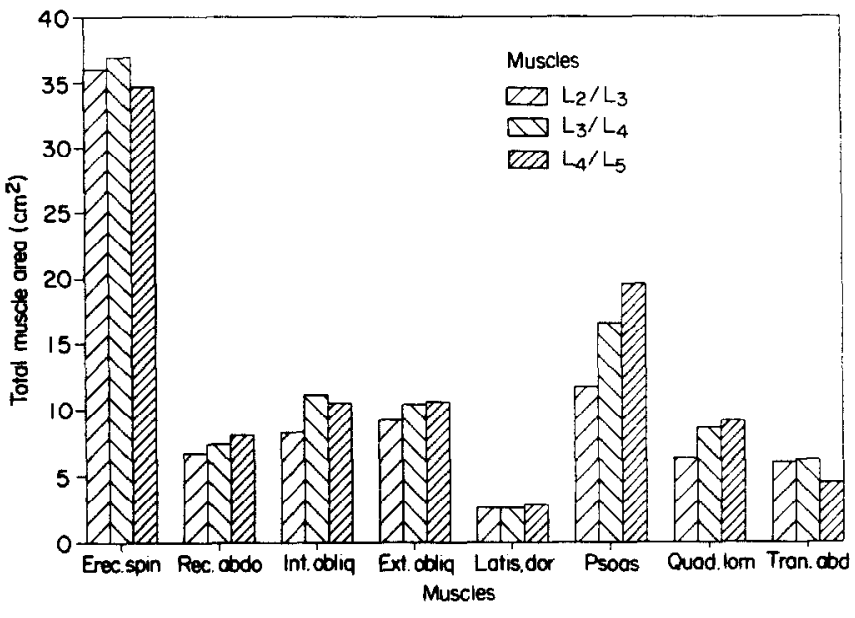

Figure 3. Muscle areas stratified by spinal motion segmental lovels. with an illustration of the relative moment arm changes at each level. In general, the evaluation indicated that the psoas moved forward and laterally while increasing in size as it descended. The quadratus lumborum followed a similar pattern to the psoas. Latissimus dorsi also displayed a similar change in location (i.e. moved forward and outward), but showed no discernable change in size. The oblique and transverse abdominals displayed significant but smaller changes in moment arm locations and cross-sections. The erector spinae and rectus abdominis moment arm locations and cross-sections were not found to change at the different levels.

These results have direct implications for the development of biomechanical models of the torso, such as those reviewed recently by Chaffin ${ }^{1.5}$ and $\mathrm{McGill}$ et al. ${ }^{9}$ In particular, the varying locations and sizes of psoas. quadratus lumborum and latissimus dorsi muscles at the

Teblo 4. Significant regressions of muscie areas $\left(\mathrm{cm}^{2}\right)$ versus height $\left(h t\right.$ in $\mathrm{cm}$ ), weight (wt in $\mathrm{kg}$ ), and torso area (tarea in $\left.\mathrm{cm}^{2}\right)$

\begin{tabular}{lllll}
\hline \multicolumn{1}{c}{ Muscle } & \multicolumn{1}{c}{ Bestmodel } & $r^{2}$ & $P$ & Standard error \\
\hline Erector spinae & $6.7+0.1166 w t+0.017 h t$ & 0.26 & $<0.001$ & $14 \%$ \\
& $14.7+0.0065$ tarea & 0.12 & $<0.001$ & $16 \%$ \\
Psoas & $9.0+0.079 w t-0.0362 h t$ & 0.18 & $<0.001$ & $24 \%$ \\
& $5+0.007$ tarea & 0.23 & $<0.0001$ & $24 \%$ \\
\hline
\end{tabular}

Table 5. Significant regression of y moment arms (in sagittal plane) versus height ( $h$ t in $\mathrm{cm}$ ), weight (wt in $\mathrm{kg}$ ), trunk breadth (tdiamx in $\mathrm{cm}$ ), trunk depth (tdiamy in $\mathrm{cm}$ ) and torso area (tarea in $\mathrm{cm}^{2}$ )

\begin{tabular}{|c|c|c|c|c|}
\hline Muscle & Bestmodel & $r^{2}$ & $P$ & Standard error \\
\hline Rectus abdominis & $\begin{array}{l}10.1+0.1034 w t-0.063 \mathrm{ht} \\
-1.6+0.40 \text { tdiamx } \\
-1.0+0.6 \text { tdiamy } \\
2.71+0.008 \text { tarea }\end{array}$ & $\begin{array}{l}0.45 \\
0.36 \\
0.63 \\
0.55\end{array}$ & $\begin{array}{l}<0.0001 \\
<0.001 \\
<0.001 \\
<0.0001\end{array}$ & $\begin{array}{l}20 \% \\
21 \% \\
16 \% \\
17 \%\end{array}$ \\
\hline
\end{tabular}


Tabb 6. Significant regression of $x$ moment arms (in coronal plane) versus height ( $h t$ in $\mathrm{cm}$ ), weight ( $w t$ in $\mathrm{kg}$ ), trunk breadth (tdiamx in $\mathrm{cm}$ ), trunk depth (tdiamy in $\mathrm{cm}$ ) and torso area (tarea in $\mathrm{cm}^{2}$ )

\begin{tabular}{|c|c|c|c|c|}
\hline Muscle & Bestmodel & $r^{2}$ & $P$ & Standard error \\
\hline Rectus abdominis & $\begin{array}{l}5.7+0.0572 w t-0.0335 \mathrm{ht} \\
-0.45+0.21 \text { tdiamix } \\
0.51+0.27 \text { tdiamy } \\
2.03+0.004 \text { tarea }\end{array}$ & $\begin{array}{l}0.41 \\
0.30 \\
0.38 \\
0.4\end{array}$ & $\begin{array}{l}<0.001 \\
<0.001 \\
<0.001 \\
<0.001\end{array}$ & $\begin{array}{l}18 \% \\
20 \% \\
18 \% \\
18 \%\end{array}$ \\
\hline Internal oblique & $\begin{array}{l}15.8+0.1 w t-0.067 h t \\
2 \cdot 16+0.418 \text { tdiamx } \\
4.6+0.5 \text { tdiamy } \\
6.4+0.008 \text { tarea }\end{array}$ & $\begin{array}{l}0.62 \\
0.64 \\
0.65 \\
0.54\end{array}$ & $\begin{array}{l}<0.001 \\
<0.001 \\
<0.001 \\
<0.0001\end{array}$ & $\begin{array}{r}8 \% \\
8 \% \\
7 \% \\
10 \%\end{array}$ \\
\hline External oblique & $\begin{array}{l}17+0.1034 w t-0.075 h t \\
2 \cdot 8+0.45 \text { tdiamx } \\
5.262+0.5 \text { tdiamy } \\
8.0+0.008 \text { tarea }\end{array}$ & $\begin{array}{l}0.56 \\
0.5 \\
0.52 \\
0.56\end{array}$ & $\begin{array}{l}<0.001 \\
<0.001 \\
<0.001 \\
<0.001\end{array}$ & $\begin{array}{r}9 \% \\
10 \% \\
10 \% \\
9 \%\end{array}$ \\
\hline Latissimus dorsi & $\begin{array}{l}6.0+0.07 w t \\
2.4+0.38 \text { tdiam } x \\
5.4+0.39 \text { tdiamy } \\
7.4+0.0065 \text { tarea }\end{array}$ & $\begin{array}{l}0.42 \\
0.52 \\
0.43 \\
0.51\end{array}$ & $\begin{array}{l}<0.001 \\
<0.001 \\
<0.0001 \\
<0.001\end{array}$ & $\begin{array}{r}10 \% \\
9 \% \\
10 \% \\
10 \%\end{array}$ \\
\hline Transverse abdominis & $\begin{array}{l}13.6+0.097 \text { wt }-0.06 \mathrm{ht} \\
1.90+0.41 \text { tdiamx } \\
4.24+0.48 \text { tdiamy } \\
7.0+0.0075 \text { tarea }\end{array}$ & $\begin{array}{l}0.56 \\
0.58 \\
0.61 \\
0.65\end{array}$ & $\begin{array}{l}<0.001 \\
<0.0001 \\
<0.0001 \\
<0.0001\end{array}$ & $\begin{array}{l}9 \% \\
8 \% \\
8 \% \\
8 \%\end{array}$ \\
\hline
\end{tabular}
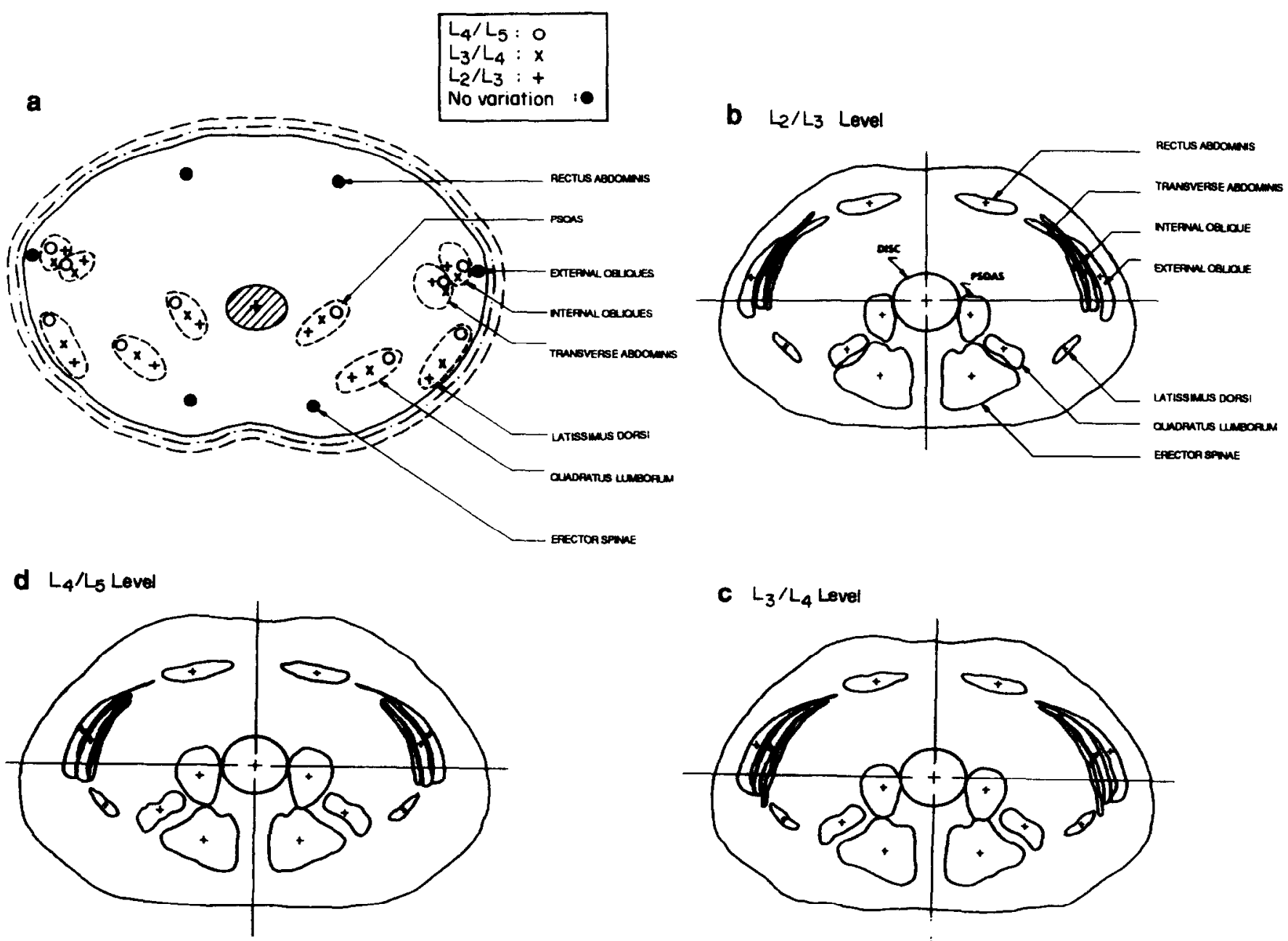

Figure 4. Illustration of how the moment arm values change at each disc level (a) together with computer projections of mean muscle size and location data at three lumbar levels $(b-d)$. 
different segmental levels must now be considered when estimating their moment reactions, especially during lateral load handling. Although these data can be used as approximations for determining the physiological crosssections and moment arms in various models, they should not be over-interpreted. The true moment arm values and muscle tensions can only be determincd from detailed studies of muscle fibre orientation and composition.

The population in this study disclosed significant but low correlations between gross anthropometry and cross-sectional areas for the erector spinae and psoas muscles. This was similar to the results reported by Reid et al. ${ }^{8}$ for active males using step-wise regression on 27 different anthropometric variables. The male subjects of McGill et al. ${ }^{9}$ showed similar results for the psoas, but not for the erector spinae. A recent study by Tracy et al. $^{16}$ also confirmed the positive correlation in the psoas with body weight in younger male subjects, but not for the erector spinae. Why the size of the psoas is consistently correlated with body weight in these three studies is worthy of future research. Since the psoas acts on relatively short moment arms but is the second largest trunk muscle, its biomechanical effects must be considered in more refined models of the torso. Indeed, if it acts as a major stabilizer of the column, particularly during lateral bending activities, it would cause larger compression forces on the discs than are currently predicted by linear optimization models which tend to utilize muscles acting with larger moment arms than those associated with the psoas (Bean et al. ${ }^{17}$ ).

The reason that the size of the erector spinae in two previously reported studies of males did not correlate with body weight (as was found in this study) may be because the size of these muscles depends more on the physical requirements placed on them during normal manual activities and not on simple gross body weight. In the older female population, body weight may be a major determinant of the loads placed on the spine, since this group may not be involved in the lifting and carrying of heavy objects as often as younger males. This line of conjecture suggests the need to know more about the subjects than simply body weight, stature and other anthropometry if one is to accurately predict muscle size. Measurements of muscle strength, combined with a knowledge of the habitual manual activities performed by the individuals, may be better correlated with torso muscle size than those variables included in this and previously reported studies.

The use of gross torso anthropometry, body weight and stature to predict muscle moment arms (as suggested by Reid et al. ${ }^{8}$ ) was evaluated in this study and disclosed that the sagittal plane $y$ moment arm for the rectus abdominis was positively correlated with both $x$ and $y$ torso diameters and body weight. This was a similar result to that reported by Tracy et al. ${ }^{16}$ for male subjects. No other muscle $y$ moment arms were correlated with these anthropometric variables. The lack of correlation with the erector spinae $y$ moment arm dimensions is in contrast to the results reported earlier
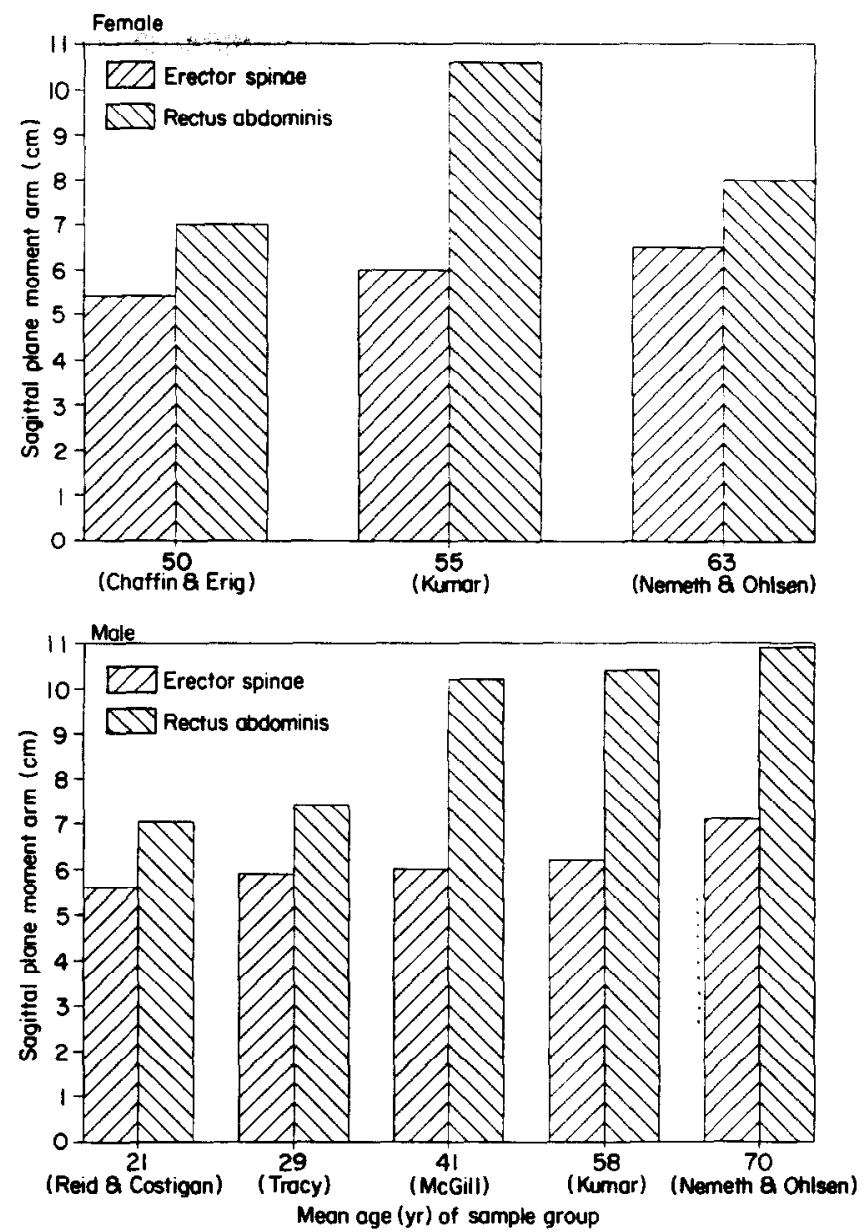

Figure 5. Comparison of erector spinae and rectus abdominis moment arms for male and female populations of varying ages from different studies.

by Reid et al. ${ }^{\gamma}$ for 20 males using a stepwise regression procedure which systematically attempted to use 27 different anthropometric variables to explain the variance in the erector spinae locations. This same study by Reid et al. also reported that the $y$ moment arm distances for the rectus abdominis did not correlate with any of their anthropometric variables, which is different from the present study and also from the results of Tracy et al. ${ }^{16}$ It should be noted that $\mathrm{Kumar}^{10}$ reported no significant correlations of the $\boldsymbol{x}$ and $\boldsymbol{y}$ moment arm lengths with body weight and stature for 35 males and 21 females.

The present study demonstrated relatively high correlations of the oblique muscle $x$ (lateral) moment arm dimensions with body weight and $x$ and $y$ torso diameters. This is in general agreement with the results of Tracy et al. ${ }^{16}$ for males. The transverse abdominis and latissimus dorsi muscle $\boldsymbol{x}$ (lateral) moment arms were also found to be positively correlated with body weight and $x$ and $y$ torso diameters in the present study.

It is interesting to compare the moment arm values obtained by the various studies cited in this discussion. Only the values for the $y$ (sagittal plane) dimensions of the erector spinae and rectus abdominis were consistently available in these studies. These are plotted with reference to the mean age of each sample population 
in Figure 5. When presented in this fashion it appears that age, in men, may have a very important effect on the rectus abdominis moment arms (possibly increasing in value by $30 \%$ ) particularly during their 30 s. Data for a larger age range of females are needed to determine if a similar effect exists. It should be noted that Kumar's data for females are based on a small sample of five subjects with widely varying ages ${ }^{\text {(1) }}$.

The erector spinae moment arm data did not show as great an age effect for both males and females though a slight increase with age is noted. Because of differences in measurement techniques and scaling factors, the variations between studies are only interesting in a qualitative sense. A cross-sectional population study of people of varying ages and gender is needed to determine the robustness of the results. It should be clear that the methods for performing such a study are quickly being developed and refined. It is hoped that this paper will add to the database that is needed to construct better three-dimensional biomechanical models of the back and will also indicate some of the causes of variation that exist in the data reported by other groups.

\section{Acknowledgements}

The authors wish to acknowledge support for this study from both the Chrysler Corporation's Technology Access Fund and the Association of American Railroads. Assistance with data gathering and statistical analysis was provided by Susan Khory. Jeff Wille. Richard Hughes and George Liu, to whom the authors are indebted. In addition, the authors would like to thank Drs Michael Flynn and Dianna Cody at the Henry Ford Hospital in Detroit for providing the CT image database as well as valuable insight and direction.

\section{References}

1 Chaffin DB, Andersson GBJ. Page G. Bloswick D. Lowback muscle models - a sensitivity analysis. Proc of ASB. Ann Arbor, MI, 1985
2 McGill SM, Norman RW. Effects of an anatomically detailed erector spinae model of $\mathrm{L}_{4} / \mathrm{L}_{5}$ disc compression and shear. J Biomech 1987; 20: 591-600

3 Bogduk N. A reappraisal of the anatomy of the human lumbar erector spinae. J Anat 1980; 131: 525-40

4 Macintosh JE. Bogduk N. The biomechanics of the lumbar multifidus. Clin Biomech 1986; 1: 205-13

5 McGill SM, Norman RW. Partitioning of the $\mathrm{L}_{4}-\mathrm{L}_{5}$ dynamic moment into disc, ligamentous, and muscular components during lifting. Spine 1986: 11: 666-78

6 Reid JG. Physical properties of the human trunk as determined by computed tomography. Arch Phys Med Rehabil 1984; 65: 246-50

7 Németh G, Ohlsén H. Moment arm lengths of trunk muscles to the lumbosacral joint obtained in vivo with computed tomography. Spine 1986;11: 158-60

8 Reid JG, Costigan PA, Comrie W. Prediction of trunk muscle areas and moment arms by use of anthropometric measures. Spine 1987; 12: 273-5

9 McGill SM, Patt N, Norman RW. Measurement of the trunk musculature of active males using $C T$ scan radiography: implications for force and moment generating capacity about the $L_{4} / L_{5}$ joint. J Biomech 1988 ; 21: 329-41

$10 \mathrm{Kumar}$ S. Moment arms of spinal musculature determined from CT scans. Clin Biomech 1988; 3: 137-44

11 Svensson H, Andersson G, Johansson S, Wilhelmsson C, Vedin A. A retrospective study of low-back pain in 38 to 64-year old women. Spine 1988; 13: 548-52

12 Yonganandan N, Myklebust J, Cusick J, Wilson C, Sances A. Functional biomechanics of the thoracolumbar vertebral cortex. Clin Biomech 1988; 3: 11-18

13 Brinckmann P, Biggermann M, Hilweg D. Fatigue fracture of human lumbar vertebrae. Clin Biomech 1988; Suppl 1

14 Cody DD. Flynn MJ, Vickers DS. A technique for measuring regional bone mineral density (rBMC) in human lumbar vertebral bodies. Medical Physics, (in press)

15 Chaffin DB. Biomechanical modelling of the low back during load lifting. Ergonomics 1988; 31: 685-97

16 Tracy MF, Gibson MJ, Szypryt EP. Rutherford A. Corlett EN. The geometry of the muscles of the lumbar spine determined by magnetic resonance imaging. Spine 1989; 14: $186-93$

17 Bean JC, Chaffin DB, Schultz AB. Biomechanical model calculation of muscle contraction forces: a double linear programming method. J Biomech 1988; 21: 59-66 